\title{
Impaired Carbohydrate Metabolism of Polymorphonuclear Leukocytes in Glycogen Storage Disease lb
}

\author{
Nava Bashan, Yocheved Hagai, Ruth Potashnik, and Shimon W. Moses \\ Pediatric Research Laboratory, Soroka Medical Center, Beer-Sheva 84101, Israel; and Faculty of Health Sciences, \\ Ben-Gurion University of the Negev, Beer-Sheva 84105, Israel
}

\begin{abstract}
This study measures hexose monophosphate (HMP) shunt activity, glycolytic rate, and glucose transport in PMN and lymphocytes of patients with glycogen storage disease (GSD) type Ib as compared with controls and with GSD Ia patients. HMP shunt activity and glycolysis were significantly lower in intact PMN cells of GSD Ib patients as compared with GSD Ia patients and with controls. These activities were above normal levels in disrupted GSD Ib PMN. HMP shunt activity and glycolytic rates in lymphocytes were similar in all three groups studied. The rate of 2-deoxyglucose transport into GSD Ib PMN was $30 \%$ of that into cells of normal controls. In GSD Ib lymphocytes or in GSD Ia PMN and lymphocytes transport was normal. The striking limitation of glucose transport across the cell membrane of the PMN of GSD Ib patients may account for the impairment of leukocyte function that is characteristic of GSD Ib, but not found in GSD Ia patients.
\end{abstract}

\section{Introduction}

Glycogen storage disease (GSD) ${ }^{1}$ type $I$ is a metabolic disease caused by a defect in the activity of glucose-6-phosphatase (D-glucose-6-phosphate phosphohydrolase, EC 3.1.3.9) (G6Pase), normally present in liver, kidney, and intestinal mucosa cells $(1,2)$.

Hepatic glucose-6-phosphatase is part of the multicomponent system of the endoplasmic reticulum (3). In 1975, Arion postulated that at least three components of the endoplasmic reticulum participate in the process of glucose-6-phosphate (G6P) hydrolysis: (a) a G6P specific translocase that shuttles G6P across the membrane; $(b)$ a relatively nonspecific phosphohydrolase located on the luminal surface of the membrane; and $(c)$ a translocase which mediates phosphate efflux out of the cisternae of the endoplasmic reticulum $(4,5)$.

Three groups of patients with GSD I have been identified:

This paper was presented in part at the ESPR Meeting, Groningen, The Netherlands, 1986.

Address reprint requests to Dr. N. Bashan, Pediatric Research Laboratory, Soroka Medical Center, Beer-Sheva 84101, Israel.

Received for publication 11 February 1987 and in revised form 19 October 1987

1. Abbreviations used in this paper: G6P, glucose-6-phosphate; GSD, glycogen storage disease; HMP, hexose monophosphate; KRP, KrebsRinger phosphate buffer.

J. Clin. Invest.

(c) The American Society for Clinical Investigation, Inc. 0021-9738/88/05/1317/06 \$2.00

Volume 81, May 1988, 1317-1322 (a) GSD Ia patients, whose liver specimens lack the enzyme G6Pase (1); (b) GSD Ib patients, whose translocase for G6P in the microsomal membrane is defective $(5,6)$; and (c) GSD Ic patients, who lack the translocase for phosphate (7).

Patients with GSD Ib suffer from recurrent bacterial infections related to neutropenia and impairment of neutrophil functions $(8,9)$.

In most patients with GSD Ib, defects in random and direct cell migration $(10,11)$, bactericidal activity $(12)$, phagocytosis (13), superoxide anion production $(11,14)$, and hexose monophosphate (HMP) activity (14) have been described. Since these functions all depend on an adequate supply of energy and NADP, we studied HMP shunt activity, glycolytic activity, ATP concentration, and glucose transport in PMN of three GSD Ib patients as compared with controls.

\section{Methods}

\section{Patients}

GSD was diagnosed on liver biopsies: GSD Ia by the absence of G6Pase activity, and GSD Ib by a high latency, i.e., low activity of G6Pase in fresh homogenates and normal activity in disrupted microsomes (15). The three GSD Ib patients suffered from numerous infections. The clinical and therapeutic data of the three GSD Ib patients and the one GSD Ia patient are summarized in Table I. There were no differences in the therapeutic management and the nutritional support of the patients. Studies of PMN were performed on preparations with initial cell counts of $600-1,500$ cells $/ \mu$ l.

\section{Cell preparation}

PMN and lymphocytes were separated from heparinized venous blood by the Ficoll-Hypaque centrifugation methods (11). $20 \mathrm{ml}$ fresh blood was mixed with 2 vol of $3 \%$ dextrane in $0.85 \% \mathrm{NaCl}$. After $1 \mathrm{~h}$ at $4^{\circ} \mathrm{C}$ the supernatant was layered on top of a Ficoll-Paque (Pharmacia Fine Chemicals, Inc., Uppsala, Sweden) at a ratio of $6 \mathrm{ml}$ of cell suspension to $3 \mathrm{ml}$ of Ficoll. This was then centrifuged at $400 \mathrm{~g}$ for $30 \mathrm{~min}$ at $5^{\circ} \mathrm{C}$. The interface layers were removed for lymphocyte preparation and the pellet for PMN preparation. Contaminating red cells were removed by the addition of $6 \mathrm{ml}$ distilled $\mathrm{H}_{2} \mathrm{O}$ for $20 \mathrm{~s}$, and isotonicity was established by the addition of $2 \mathrm{ml} \mathrm{3.5 \%} \mathrm{NaCl}$.

Cells were suspended in Krebs-Ringer phosphate (KRP) buffer and counted in a hemocytometer. Cell suspensions were then adjusted to $10 \times 10^{6}$ cells $/ \mathrm{ml}$.

\section{Activity of the HMP Shunt}

In intact cells. The activity of the HMP shunt was determined by a modification of the method described by Newburger et al. (16). Leukocytes were suspended in KRP $\left(10^{6}\right.$ cells $\left./ \mathrm{ml}\right)$ with $2 \mathrm{mM}\left[1-{ }^{14} \mathrm{C}\right]-$ glucose $(0.5 \mu \mathrm{Ci} / \mathrm{ml})$ and $1 \mathrm{mM}$ methylene-blue. Incubation was performed in sealed tubes with a central well containing filter paper impregnated with $200 \mu \mathrm{l}$ hyamine hydroxide. After $1 \mathrm{~h}$ of incubation at $37^{\circ} \mathrm{C}, 0.5 \mathrm{ml}$ of $2 \mathrm{~N} \mathrm{H}_{2} \mathrm{SO}_{4}$ was added to stop the reaction and to release ${ }^{14} \mathrm{CO}_{2}$ from the solution. The tubes were subsequently agitated for another $30 \mathrm{~min}$. The filter paper was removed and placed in vials filled with a toluene-based scintillation fluid, and radioactivity was 
Table I. Laboratory Data of the Patients Studied

\begin{tabular}{|c|c|c|c|c|}
\hline & \multicolumn{3}{|c|}{ GSD Ib patients } & \multirow{2}{*}{$\frac{\text { GSD Ia }}{\text { T.Y. }}$} \\
\hline & L.S. & A.A. & N.T. & \\
\hline Age $(y r)$ & 13 & 4 & 3 & 3 \\
\hline Lactic acid $(m M)$ & 3.1 & 3.7 & 2.9 & 2.8 \\
\hline Uric acid $(m g / d l)$ & 4.7 & 7.0 & 5.7 & 7 \\
\hline Cholesterol $(m g / d l)$ & 98 & 128 & 173 & 230 \\
\hline Serum glutamic oxaloa & & & & \\
\hline transaminase $(I U)$ & 150 & 187 & 353 & 174 \\
\hline $\begin{array}{l}\text { Serum glutamic pyruvic } \\
\text { transaminase }(I U)\end{array}$ & 108 & 95 & 230 & 168 \\
\hline $\mathrm{Hb} \mathrm{A}_{1} \mathrm{C}(\%)$ & 5.5 & 4.2 & 3.8 & 5.4 \\
\hline $\begin{array}{l}\text { Total leukocytes (cells/ } \\
\mathrm{mm}^{3} \text { ) }\end{array}$ & 3,100 & 5,700 & 5,500 & 13,000 \\
\hline $\begin{array}{c}\text { PMN (\% of total } \\
\text { leukocytes) }\end{array}$ & 24 & 27 & 15 & 28 \\
\hline
\end{tabular}

determined in a scintillation spectrometer (Tricarb; Packard Instruments, Downers Grove, IL).

In disrupted cells. Cells were suspended in KRP containing 1\% Triton-X100. HMP shunt activity was measured as described for intact cells, in the presence of $0.75 \mathrm{mM}$ NADP and $0.75 \mathrm{mM}$ ATP.

\section{Glycolytic activity}

In intact cells. Glycolytic activity was measured as described earlier (17): leukocytes $\left(1.5-3 \times 10^{6}\right)$ were incubated at $37^{\circ} \mathrm{C}$ in a medium containing $100 \mathrm{mM}$ Hepes buffer, $5 \mathrm{mM} \mathrm{KCl}, 80 \mathrm{mM} \mathrm{NaCl}, 1.2 \mathrm{mM}$ $\mathrm{MgSO}_{4}, 2.5 \mathrm{mM} \mathrm{CaCl}_{2}, 0.2 \mathrm{mM} \mathrm{NaH}_{2} \mathrm{PO}_{4}$, and $2.5 \mathrm{mM}$ glucose, $\mathrm{pH}$ 7.6 , in a final volume of $0.5 \mathrm{ml}$. Lactate production was determined as described previously (18).

In disrupted cells. Cells $\left(1.5-3 \times 10^{6}\right)$ were suspended in KRP containing $1 \%$ Triton X-100, $5 \mathrm{mM}$ glucose, $1 \mathrm{mM}$ ATP, and $0.7 \mathrm{mM}$ NAD. Lactate production was measured as in intact cells.

\section{Glucose transport}

Uptake of 2-deoxyglucose was measured as previously described (19). $2 \times 10^{6}$ purified PMN or lymphocytes-monocytes were suspended in 1 $\mathrm{ml} \mathrm{KRP}$ containing $5 \mu \mathrm{Ci} / \mathrm{ml}\left[1-{ }^{3} \mathrm{H}\right] 2$-deoxyglucose at concentrations indicated in the legends. Suspensions were incubated at $37^{\circ} \mathrm{C}$, and uptake was stopped at various time intervals by adding $1 \mathrm{ml}$ cold $0.9 \%$ $\mathrm{NaCl}$. The samples were centrifuged at $3,000 \mathrm{~g}$ for $3 \mathrm{~min}$ and the pellets were washed twice with $2 \mathrm{ml}$ cold $0.9 \% \mathrm{NaCl}$ and centrifuged. The final pellet was dissolved in $0.5 \mathrm{ml}$ water, and after repeated freeze-thawing procedures, samples were taken for determination of radioactivity and protein.

\section{Phosphorylation of 2-deoxyglucose}

PMNs $\left(1 \times 10^{6}\right)$ were incubated at $37^{\circ} \mathrm{C}$ in a shaking bath for different lengths of time in a final volume of $60 \mu \mathrm{l}$ containing $1 \mathrm{mmol} / \mathrm{liter}$ $\left[1-{ }^{3} \mathrm{H}\right]$-2-deoxyglucose $(0.2 \mu \mathrm{Ci})$. The reaction was stopped by chilling in ice. The samples were centrifuged at $3,000 \mathrm{~g}$ for $2 \mathrm{~min}$. The pellets were then washed three times in $0.9 \% \mathrm{wt} / \mathrm{vol} \mathrm{NaCl}$. The final pellets were suspended in $1 \mathrm{ml}$ water and boiled for $5 \mathrm{~min}$ in a water bath. Subsequently, denatured protein was removed by centrifugation at $27,000 \mathrm{~g}$ for $10 \mathrm{~min}$. The entire supernatant was applied to a small column of Dowex-1-Cl-resin $(10 \mathrm{~cm} \times 1 \mathrm{~cm})$ as previously described (19). The column was washed with $30 \mathrm{ml}$ of $\mathrm{H}_{2} \mathrm{O}$ to elute free 2-deoxyglucose, and fractions of $0.5 \mathrm{ml}$ were collected. The column was then washed with $30 \mathrm{ml}$ of $0.5 \mathrm{~mol} / \mathrm{liter} \mathrm{HCl}$ to remove deoxyglucose-6phosphate, and $0.5-\mathrm{ml}$ fractions were collected. Each fraction was added to $5 \mathrm{ml}$ Instagel and the radioactivity was measured in a liquid scintillation spectrometer.

\section{Osmotic fragility of $P M N$}

$0.4 \times 10^{6}$ cells were incubated at room temperature for $30 \mathrm{~min}$ in different $\mathrm{NaCl}$ concentrations $(0-0.8 \% \mathrm{wt} / \mathrm{vol})$. At the end of incubation, cells were centrifuged for $10 \mathrm{~min}$ at $3,000 \mathrm{~g}$. Lactate dehydrogenase activity in the supernatant was measured as described (20).

\section{Efflux of 2-deoxyglucose}

$10^{6}$ cells were incubated in $\mathrm{KRP}$ with $\left[1-{ }^{3} \mathrm{H}\right] 2$-deoxyglucose $(1.5 \mathrm{mM}$, $0.2 \mu \mathrm{Ci}$ ) in a final volume of $60 \mu \mathrm{l}$. Control cells were incubated for 20 min and patients' cells for $60 \mathrm{~min}$. After subsequent washes in cold $\mathrm{KRP}$, the cells were incubated in KRP at $37^{\circ} \mathrm{C}$. At different time intervals, portions were removed and centrifuged at $3,000 \mathrm{~g}$ for $10 \mathrm{~min}$ at $4^{\circ} \mathrm{C}$, and pellets and supernatants were counted for radioactivity.

ATP concentration in the PMN was measured by the luciferin-luciferase method (21). Glycogen concentration in the PMN was measured after alcohol precipitation as previously described (22). Activities of hexokinase, G6P, and 6-phosphogluconate dehydrogenases were measured as described previously (18). Protein concentration was determined by the Lowry method (23).

\section{Statistical analysis}

Data are presented as the mean $\pm \mathrm{SD}$. For each assay, at least three observations were performed on separate occasions, unless otherwise indicated. The $t$ test was used to compare the mean value of control assays with those of GSD Ib patients $(n=3)$. As only two GSD Ia patients were tested, no statistical analysis was performed.

\section{Materials}

$D-\left[1-{ }^{3} \mathrm{H}\right] 2-\mathrm{Deoxyglucose}$ and $\mathrm{D}-\left[1-{ }^{14} \mathrm{C}\right]$ glucose were purchased from Amersham Corp. Radiochemical Centre, Amersham, England. All other chemicals were purchased from Sigma Chemical Co., St. Louis, MO.

\section{Results}

HMP shunt activity in intact PMN of GSD Ib patients (Fig. 1 $B$ ) was about one-third of that found in PMN of normal controls (Fig. $1 A$ ); HMP activity in disrupted cells of GSD Ib

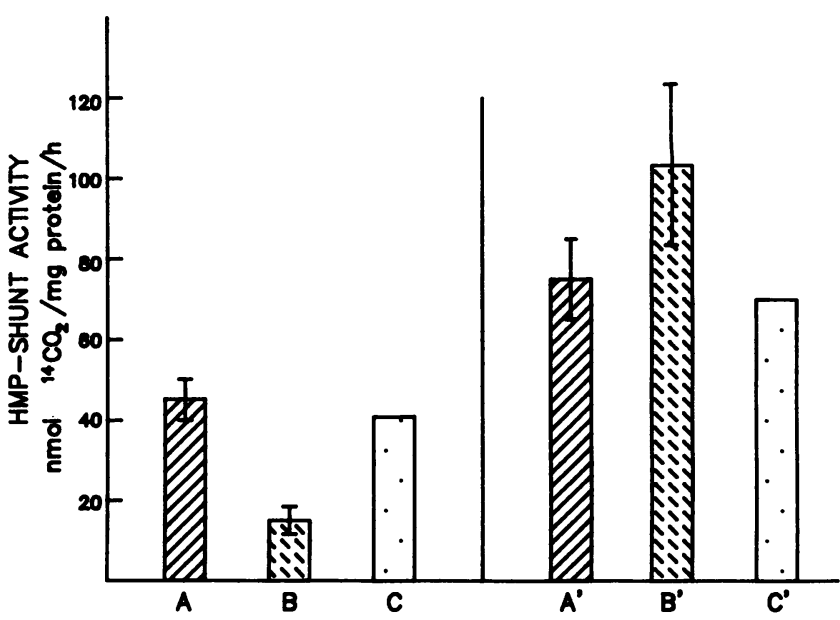

Figure 1. HMP shunt activity in intact and disrupted PMN of three GSD Ib patients and two GSD Ia patients as compared with controls. HMP shunt activity in intact and disrupted PMN was measured as described in Methods. $A$ and $A^{\prime}$, intact and disrupted control $\operatorname{PMN}(n=12) ; B$ and $B^{\prime}$, intact and disrupted GSD Ib PMN $(n=3)$; and $C$ and $C^{\prime}$, intact and disrupted GSD Ia PMN $(n=2)$. The significant difference between $A$ and $B$ values was $P<0.001$; between $A$ and $A^{\prime}$ values, $P<0.005$; between $B$ and $B^{\prime}$ values, $P<0.001$; and between $A^{\prime}$ and $B^{\prime}$ values, $P<0.01$. 
Table II. Activities of Glucose-6-Phosphate Dehydrogenase (G6PD), 6-Phosphogluconate Dehydrogenase (6PGD), and Hexokinase in PMN

\begin{tabular}{lcc}
\hline & Control & GSDIb \\
\hline & \multicolumn{2}{c}{$n$ mol/10 cells per min } \\
Hexokinase & $2.6 \pm 0.5$ & $2.4 ; 3.0$ \\
G6PD & $2.3 \pm 0.3$ & $2.3 ; 1.7$ \\
6PGD & $0.50 \pm 0.07$ & $0.52 ; 0.74$ \\
\hline
\end{tabular}

Assays were carried out in duplicate on samples from five controls and two GSD Ib patients.

patients (Fig. $1 B^{\prime}$ ) was higher than in those from controls and one GSD Ia patient (Fig. $1, A^{\prime}$ and $C^{\prime}$ ). Table II shows that the activities of the rate-limiting enzymes of glycolysis and the HMP shunt-hexokinase, G6P, and 6-phosphogluconate dehydrogenase-were normal. During infections, HMP shunt activity in PMN of GSD Ib patients increased to the level found in cells from controls (Table III). HMP shunt activity in PMN of patients suffering from recurrent familiar neutropenia was found to be within the normal range both in intact and in disrupted cells (Table III). In lymphocytes of GSD Ib, GSD Ia, and controls, HMP shunt activity was in the same range in both intact and disrupted cells (Fig. 2).

Glycolytic activity of PMN was determined by lactate production from glucose (Fig. 3). In intact cells of GSD Ib patients (Fig. $3 \mathrm{~B}$ ), lactate production was $50 \%$ of that in controls (Fig. $3 \mathrm{~A}$ ). In the absence of glucose lactate production from the endogenous substrate, there was no difference between control and GSD Ib patients $\left(12 \pm 4\right.$ and $10.8 \mathrm{nmol} / 10^{6}$ per $\mathrm{h}$, respectively). In disrupted PMN, glycolytic activity in all groups was similar. In lymphocytes, the glycolytic activity of both GSD Ia and GSD Ib patients did not differ from that in controls (data not shown).

As glycogen can serve as a substrate for lactic acid production, we measured glycogen concentrations in PMN of two GSD Ib patients. Glycogen concentrations in A.A.'s and L.S.'s PMN were found to be 20 and $28 \mathrm{mg} / 10^{6}$ cells, respectively, which is not significantly different from the glycogen concentration in control PMN: $25 \pm 7 \mathrm{mg} / 10^{6}$ cells.

The reduced activity of both HMP shunt and glycolysis in intact PMN of GSD Ib patients could have been due to a reduction either in glucose transport into the cells or in the availability of cofactors such as ATP, NAD, or NADP.

Table III. Activity of HMP Shunt in PMN of GSD Ib Patients during !rfections

\begin{tabular}{|c|c|c|}
\hline & \multicolumn{2}{|c|}{ HMP shunt activity } \\
\hline & Intact & Disrupted \\
\hline & \multicolumn{2}{|c|}{$n m o l \mathrm{CO}_{2} / \mathrm{mg}$ protein per $h$} \\
\hline Controls (15) & $44 \pm 6$ & $75 \pm 15$ \\
\hline GSD Ib (3) & $17 \pm 4$ & $108 \pm 20$ \\
\hline GSD Ib during infections (3) & $39 \pm 5$ & $78 \pm 10$ \\
\hline Recurrent neutropenia (4) & $46 \pm 6$ & $90 \pm 15$ \\
\hline
\end{tabular}

Numbers of individuals examined are shown in parentheses.



Figure 2. HMP shunt activity in intact and disrupted lymphocytesmonocytes of three GSD Ib patients and two GSD Ia patients as compared with controls. $A$ and $A^{\prime}$, intact and disrupted control lymphocytes-monocytes $(n=12) ; B$ and $B^{\prime}$, intact and disrupted GSD Ib lymphocytes-monocytes $(n=3)$; and $C$ and $C^{\prime}$, intact and disrupted GSD Ia lymphocytes-monocytes $(n=2)$. There was no significant difference between $A$ and $B$ and between $A^{\prime}$ and $B^{\prime}$. The significant difference between $A^{\prime}$ and $A$ values was $P<0.001$, and between $B^{\prime}$ and $B$ values was $P<0.001$.

Glucose transport into PMN was measured with $\left[{ }^{3} \mathrm{H}\right] 2$-deoxyglucose. Fig. 4 shows that the transport of 2-deoxyglucose into control PMN was linear with time up to $5 \mathrm{~min}$, and was almost completely inhibited by $10 \mathrm{mM}$ glucose or $0.1 \mathrm{mM}$ phloretin, indicating that 2-deoxyglucose competes with glucose for entry into the cell. 2-Deoxyglucose transport into

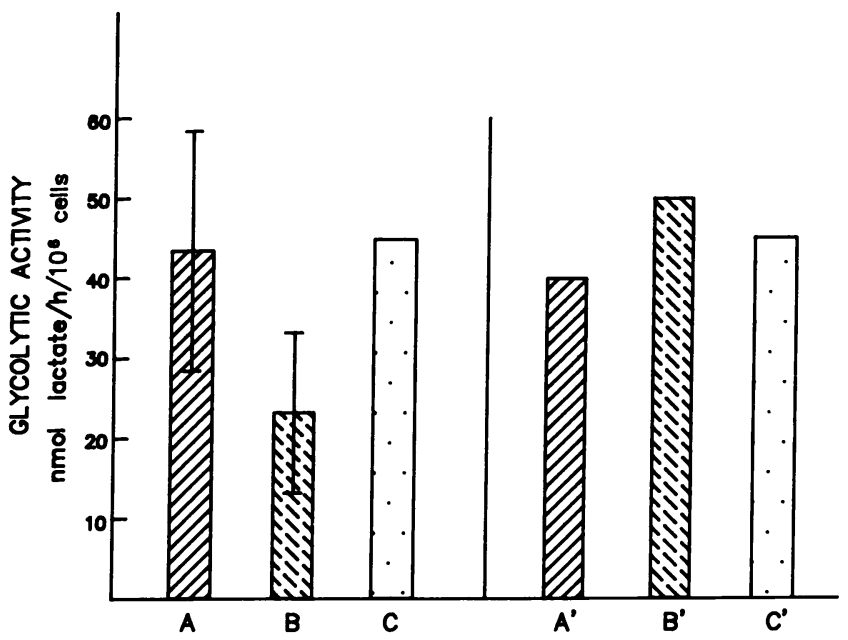

Figure 3. Glycolytic activity in intact and disrupted PMN of three GSD Ib patients and two GSD Ia patients as compared with controls. Glycolytic activity was measured by lactic acid production during $2 \mathrm{~h}$ of incubation with glucose as described in Methods. Lactic acid production was linear with time and with PMN concentrations $A$ and $A^{\prime}$, intact and disrupted control PMN (for $A, n=8$, for $A^{\prime}$, $n=3$ ); $B$ and $B^{\prime}$, intact and disrupted GSD Ib PMN (for $B, n=3$, for $B^{\prime}, n=2$ ); and $C$ and $C^{\prime}$, intact and disrupted GSD Ia PMN $(n=2)$. The significant difference between $A$ and $B$ values was $P$ $<0.01$. 


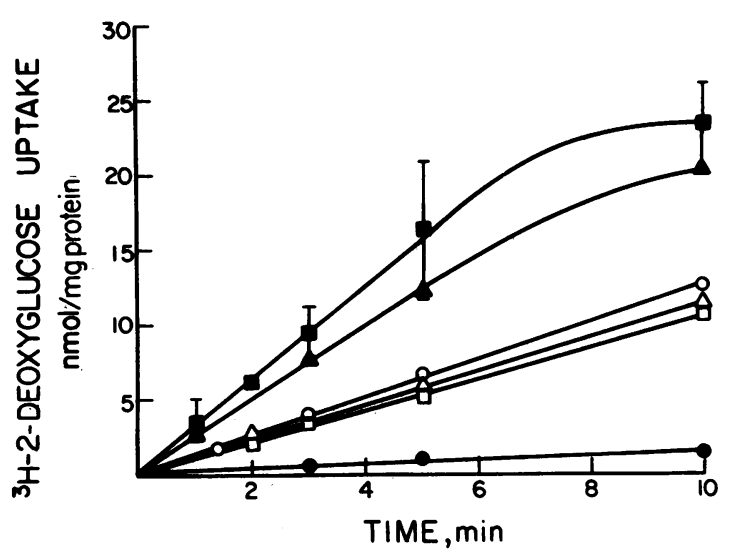

Figure 4. $\left[{ }^{3} \mathrm{H}\right] 2$-Deoxyglucose uptake by PMN of three GSD Ib patients, one GSD Ia patient, and controls. $\left[{ }^{3} \mathrm{H}\right] 2$-Deoxyglucose uptake was measured as described in Methods, at a final concentration of $2.5 \mathrm{mM}\left[{ }^{3} \mathrm{H}\right] 2$-deoxyglucose. $₫$, control PMN $(n=15)$; $\bullet$, control PMN + $10 \mathrm{mM}$ glucose; $\triangle$, Ia patient's PMN; O, Ib patient A.A.; $\Delta$, Ib patient N.T.; and $\mathrm{a}$, Ib patient L.S.

PMN of the three GSD Ib patients was only 30\% of that in controls or GSD Ia patients, and was also inhibited by $10 \mathrm{mM}$ glucose (data not shown).

Transport of 2-deoxyglucose in normal PMN clearly followed saturation type kinetics and yielded $K_{\mathrm{m}}$ and $V_{\max }$ of 0.6 $\mathrm{mmol} / \mathrm{liter}$ and $0.51 \pm 0.13 \mathrm{nmol} / \mathrm{min}$ per $10^{6}$, respectively. A similar study performed in two of the patients showed a reduced $V_{\max }$ without a significant change in $K_{\mathrm{m}}$ (Fig. 5). The rate of deoxyglucose transport into $\mathrm{PMN}$ of a patient suffering from recurrent familial neutropenia $(1,100 \mathrm{PMN}$ cells $/ \mu \mathrm{l})$ was found to be $0.47 \mathrm{nmol} / 10^{6}$ per min, which is within the normal range.

The rate of phosphorylation of 2-deoxyglucose in the cells may affect glucose transport. As phosphorylation rates depend on ATP concentration, the level of ATP in PMN of GSD Ib patients was measured. Their ATP concentration was $0.57 \pm 0.25$, as compared with $0.74 \pm 0.31 \mathrm{nmol} / 10^{6}$ cells in controls. The quantities of phosphorylated and nonphosphor-

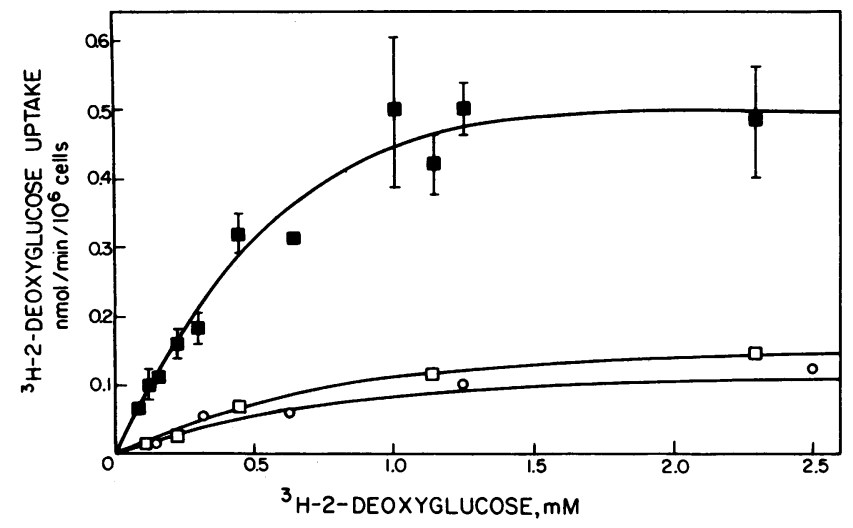

Figure 5. $\left[{ }^{3} \mathrm{H}\right] 2$-Deoxyglucose uptake by $\mathrm{PMN}$ of controls and two GSD Ib patients at different concentrations. $\left[{ }^{3} \mathrm{H}\right] 2$-Deoxyglucose uptake was measured as described in Methods at different substrate concentrations. $K_{\mathrm{m}}$ and $V_{\max }$ were calculated according to Lineweaver-Burk equation. $₫$, control PMN $(n=8)$; O, Ib patient A.A.; and $\square$, Ib patient L.S.
Table IV. Phosphorylation of $\left[{ }^{3} H\right]$ Deoxyglucose in PMN

\begin{tabular}{cll} 
& \multicolumn{2}{c}{$\begin{array}{c}\text { Ratio of }\left[{ }^{3} \mathrm{H}\right] \text { deoxyglucose-6-P } \\
\text { to }\left[{ }^{3} \mathrm{H}\right] \text { deoxyglucose }\end{array}$} \\
\cline { 2 - 3 } incubation & Control & L.S. \\
\hline $\min$ & & \\
2 & 5.2 & 5.6 \\
20 & 4.8 & 6 \\
\hline
\end{tabular}

ylated deoxyglucose in the PMN of control and L.S.'s PMN were determined after 2 and 20 min of incubation with $\left[{ }^{3} \mathrm{H}\right] 2$ deoxyglucose (Table IV). As can be seen, there was no signifcant difference in the phosphorylation of deoxyglucose between the PMN of the control and the patient.

To examine whether the cells were intact, we tested their resistance to various osmotic pressures. As can be seen in Fig. 6 , the osmotic fragility of the PMN cells of the GSD Ib patients did not differ from that of the control.

Efflux of 2-deoxyglucose from loaded PMN was measured as described in Methods. The $\left[{ }^{3} \mathrm{H}\right] 2$-deoxyglucose lost from the cells was fully accounted for by its appearance in the efflux medium. Its appearance in the supernatant increased in approximate proportion to time through at least $20 \mathrm{~min}$ of incubation. Calculations of the velocity of 2-deoxyglucose efflux were based on samples obtained between 0 and $20 \mathrm{~min}$ of incubation. The rate of efflux of GSD Ib PMN did not differ from those of control PMN (0.055 and $0.049 \mathrm{nmol} / \mathrm{min}$ per $10^{6}$, respectively).

In an additional experiment, uptakes of 2-deoxyglucose, lactate, and $\mathrm{CO}_{2}$ production were assayed on PMN from the same blood sample. In accordance with previous results, 2-deoxyglucose transport into PMN of the patient was $\sim 30 \%$ of that of the control. Glycolytic rates and HMP activity were similarly reduced in the PMN of GSD Ib patients; there was no difference, however, in the relative contribution of $\mathrm{CO}_{2}$ and lactate production in cells from the patient and the control (Table V).

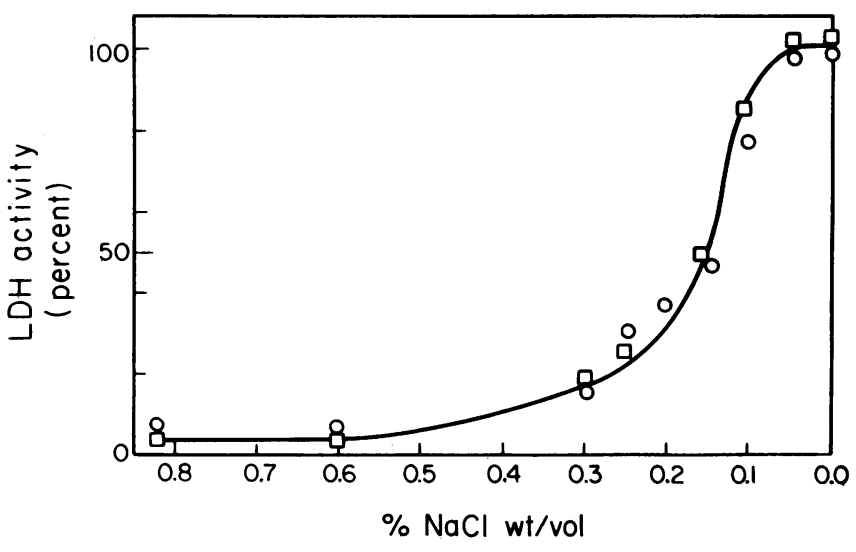

Figure 6. Osmotic fragility of PMN of GSD Ib patient and control. Osmotic fragility was measured as described in Methods. LDH activity in the supernatant after 30 min of incubation in water was considered as $100 \%$. $\square$, control; $\bigcirc$, patient A.A. 
Table V. Distribution of Glucose Metabolites between Glycolysis and HMP Shunt

\begin{tabular}{lllc}
\hline & \multicolumn{1}{c}{ GSD Ib } & \multicolumn{1}{c}{ Control } & GSD/control \\
\hline \multicolumn{4}{c}{ nmol/min per mg protein } \\
Glucose transport & $1.15(100 \%)$ & $3.70 \pm 0.4(100 \%)$ & $\%$ \\
Lactate production & $0.63(55 \%)$ & $2.00 \pm 0.2(54 \%)$ & 31.0 \\
$\mathrm{CO}_{2}$ production & $0.20(17 \%)$ & $0.70 \pm 0.06(19 \%)$ & 28.5 \\
Lactate $/ \mathrm{CO}_{2}$ & 3.1 & 2.8 &
\end{tabular}

Glucose transport, lactate, and $\mathrm{CO}_{2}$ production were measured as described in Methods in one patient and five controls on the same blood sample.

\section{Discussion}

The present study demonstrates an abnormal metabolism of PMN from patients with GSD Ib, manifested by a reduction in activity of the HMP shunt, glycolysis, and glucose transport into the cells. The reduced activities in PMN of GSD Ib patients could not be ascribed to differences in metabolic disturbances, such as recurrent hypoglycemia, lactic acidosis, or hyperuricemia, since glucose metabolism of PMN of GSD Ia patients did not differ from that of normal controls.

Our study confirms previous observations on abnormal HMP shunt activity in PMN of GSD Ib patients (11) and is in accordance with the results of Seger et al., who found a reduced oxygen burst during phagocytosis in whole cells, which was corrected by cell disruption and addition of NADPH (14). Seger (14) suggested that this reduced oxygen burst was due to a deficiency of NADPH in these cells. In the present study, NADPH levels were not measured, but low levels of NADPH cannot account for the reduced glycolytic activity; it is therefore unlikely that this could be the only defect in PMN from these patients. The present study shows that the metabolic defect in PMN of GSD Ib patients is not limited to the HMP shunt. The primary defect seems to be a reduction in the availability of G6P, causing a quantitatively similar impairment in both glycolytic and HMP shunt activity. The production of G6P in the cell depends on (a) glucose transport, $(b)$ availability of ATP, $(c)$ activity of hexokinase, and $(d)$ degradation of glycogen. In the present study, hexokinase activity and ATP concentration in cells of GSD Ib patients did not differ from those of controls, leaving a reduced transport of glucose into the cell as the most likely alternative, which was confirmed by 2-deoxyglucose transport studies.

Part of 2-deoxyglucose accumulates in the neutrophils in a phosphorylated form; thus, the amount of 2-deoxyglucose retained by the neutrophils is a function of both the transport system and of the phosphorylation step.

As is evident from Table IV, there was no reduction in the ratio of 2-deoxyglucose-6-phosphate to 2-deoxyglucose in the patients' PMN as compared with control PMN either in zero trans conditions ( 2 min of incubation) or in steady state conditions (20 min of incubation). Thus, the rate of phosphorylation of 2-deoxyglucose is probably not the cause for the reduction in 2-deoxyglucose transport into the patients' cells observed at different substrate concentrations, as is evident in Fig. 5. However, one cannot exclude the possibility that the impairment of influx is secondary to a reduction in ATP con- centrations in the presence of 2-deoxyglucose. Since glucose transport into the Ib neutrophils was diminished by $70 \%$, the reduced production of $\mathrm{C}^{14} \mathrm{O}_{2}$ through the HMP shunt could be due partly to the dilution of the radioactive G6P pool by cold G6P derived from endogenous glycogen. Yet such a dilution cannot explain the reduction in lactic acid production found in the patients' neutrophils (Fig. 3). The reason for the enhanced shunt activity found in the patients' neutrophils during infections (Table III) is not yet clear. It may be a result of activation of the HMP shunt, activation of glucose transport, or changes in the neutrophil population during infection.

The diminished rates of deoxyglucose uptake into the Ib PMN is probably not a reflection of a selected subpopulation of neutrophils, since transport of 2-deoxyglucose in PMN of a patient suffering from recurrent neutropenia was found to be within the normal range.

The diminished 2-deoxyglucose transport in the Ib PMN seems to be a specific and not a generalized defect in the membrane itself, since the osmotic fragility, which is a crude index of membrane integrity, did not differ from that of the controls (Fig. 6). Moreover, efflux of 2-deoxyglucose from loaded patient PMN was the same as in controls.

The relationship between the hepatic microsomal G6P translocase defect in the Ib patients and the neutrophil glucose transport defect is not clear. Roles of the multifunctional G6Pase system in insulin-independent glucose transport in various tissues have been suggested $(24,25)$. However, the possibility of a common subunit for glucose transport and microsomal G6P transport is unlikely, since in erythrocytes at least, the glucose transporter was found to be a single polypeptide (26).

A reduced transport of glucose into PMN can be due to a reduction in the number or activity of transporters. Synthesis of glucose transporters takes place in the endoplasmic reticulum (27) and may, in an unknown way, be directly dependent on the availability of microsomal G6P or indirectly on NADPH, a product of the microsomal hexose-6-phosphatedehydrogenase $(28,29)$. A defect in the synthesis of glucose transporters could lead to a reduction in the number of transporters or to a change in properties, resulting in reduced transport capacity. The striking reduction in glucose transport observed in the PMNs of GSD Ib patients could be responsible for the metabolic and functional deficiencies in these cells.

\section{Acknowledgments}

We are grateful to Prof. Aliza Gutman of the Department of Clinical Biochemistry, Hadassa Medical School, Jerusalem, Israel, for her assistance in the writing of this paper. In addition, we would like to thank Mrs. M. Duman for her skillful and devoted editorial assistance.

\section{References}

1. Cori, G. T., and C. F. Cori. 1952. Glucose-6-phosphate of liver in glycogen storage disease. J. Biol. Chem. 199:661-667.

2. Howell, R. R. 1978. The glycogen diseases. In The Metabolic Basis of Inherited Disease. J. B. Stanbury, J. B. Wyngaarden, and D. S. Fredrickson, eds. 5th edition. McGraw-Hill Book Co., New York. 141-166.

3. Arion, W. J., B. K. Wallin, A. J. Lange, and L. M. Ballas. 1975. On the involvement of glucose-6-phosphate transport system in the function of microsomal glucose-6-phosphate. Mol. Chem. Biochem. 6:75-83. 
4. Arion, W. J., A. J. Lange, H. E. Walls, and L. M. Ballas. 1980. Evidence for the participation of independent translocases for phosphate and glucose-6-phosphate in the microsomal glucose-6-phosphate system. J. Biol. Chem. 253:10396-10406.

5. Igarashi, Y., H. Otomo, K. Narisawa, and K. Tada. 1979. A new variant of glycogen storage disease type I probably due to a defect in the glucose-6-phosphate transport system. J. Inherited Metab. Dis. 24:4549.

6. Narisawa, K., Y. Igarashi, H. Otomo, and K. Tada. 1978. A new variant of glycogen storage disease type I due to a defect in glucose-6phosphate transport system. Biochem. Biophys. Res. Commun. 83:1360-1364.

7. Nordlie, R. C., K. A. Sukalski, J. M. Munoz, and J. J. Baldwin. 1983. Type Ic: a novel glycogenosis. J. Biol. Chem. 258:9739-9744.

8. DiRocco, M., C. Borrone, F. Dallegri, G. Frumento, and F. Patrone. 1984. Neutropenia and impaired neutrophil function in glycogenosis type Ib. J. Inherited Metab. Dis. 7:151-154.

9. Schaub, J., and K. Heyne. 1983. Glycogen storage disease type Ib. Eur. J. Pediatr. 140:283-288.

10. Beaudet, A. L., D. C. Anderson, V. V. Michels, W. J. Arion, and A. J. Lange. 1980. Neutropenia and impaired neutrophil migration in type Ib glycogen storage disease. J. Pediatr. 97:906-910.

11. Gahr, M., and K. Heyne. 1983. Impaired metabolic function of polymorphonuclear leukocytes in glycogen storage disease Ib. Eur. $J$. Pediatr. 140:329-330.

12. Koven, N. L., M. M. Clark, C. S. Cody, C. A. Stanley, L. Baker, and S. D. Douglas. 1981. Impaired chemotaxis and neutrophil (PMN) function in glycogenosis (GSD) Ib. Pediatr. Res. 14:226A. (Abstr.)

13. Heyne, K., and M. Gahr. 1980. Phagocytotic extra-respiration: differences between cases of glycogenosis type Ia and Ib. Eur. J. Pediatr. 133:186. (Abstr.)

14. Seger, R., B. Steinmann, L. Tiefenauer, T. Matsunega, and R. Gitzelmann. 1984. Glycogenosis Ib. Neutrophil microbicidal defects due to impaired hexose-monophosphate shunt. Pediatr. Res. 18:297299.

15. Narisawa, K., H. Otomo, Y. Igarashi, N. Arai, M. Otake, K. Tada, and T. Kusuya. 1983. Glycogen storage disease type Ib: microsomal glucose-6-phosphate system in two patients with different clinical findings. Pediatr. Res. 17:545-549.

16. Newburger, P. E., J. S. Pagano, J. S. Greenberger, A. Karpas, and H. J. Cohen. 1980. Dissociation of opsonised particle phagocytosis and respiratory burst activity in an Epstein-Barr-Virus infected myeloid cell line. J. Cell Biol. 85:549-557.

17. Beck, W. S. 1955. Kinetic analysis of the glycolytic rate and certain glycolytic enzymes in normal and leukemic leucocytes. J. Biol. Chem. 216:333-350.

18. Beutler, E. 1971. Red cell metabolism. A manual of biochemical methods. Grune and Stratton, Inc., New York/San Francisco/ London. 2-143.

19. McCall, C. E., D. A. Bass, S. Cousart, and L. R. DeChatelet. 1979. Enhancement of hexose uptake in human polymorphonuclear leucocytes by activated complement C5a. Proc. Natl. Acad. Sci. USA 76:5896-5900.

20. Bergmeyer, H. U., and E. Bern. 1974. In Methods of Enzymatic Analysis. 2nd edition. H. U. Bergmeyer, editor. Academic Press, Inc., New York. Vol. 2. 574.

21. Strehler, B. L. 1974. In Methods of Enzymatic Analysis. 2nd edition. H. U. Bergmeyer, editor. Academic Press, Inc., New York. Vol. 4. 2112.

22. Borregaard, N., and T. Herlin. 1982. Energy metabolism of human neutrophils during phagocytosis. J. Clin. Invest. 70:550-557.

23. Lowry, O. H., N. J. Rosebrough, A. L. Farr, and R. J. Randall. 1951. Protein measurement with the Folin phenol reagent. J. Biol. Chem. 193:265-275.

24. Nordlie, R. C. 1979. Multifunctional glucose-6-phosphatase: cellular biology. Life Sci. 24:2397-2404.

25. Nordlie, R. C. 1974. Metabolic regulation by multifunctional glucose-6-phosphatase. Curr. Top. Cell. Regul. 8:33-117.

26. Gorga, F. R., S. A. Baldwin, and G. E. Lienhard. 1979. The monosaccharide transport from human erythrocytes is heterogeneously glycosylated. Biochem. Biophys. Res. Commun. 91:955-961.

27. Cushman, S. W., and L. J. Wardzala. 1980. Potential mechanism of insulin action on glucose transport in the isolated rat adipose cell. J. Biol. Chem. 255:4758-4760.

28. Beutler, E., and M. Morrison. 1967. Localization and characteristics of hexose-6-phosphate dehydrogenase (glucose dehydrogenase). J. Biol. Chem. 242:5289-5293.

29. Mandula, B., S. K. Strirastava, and E. Beutler. 1970. Hexose6-phosphate dehydrogenase: distribution in rat tissues and effect of diet and steroids. Arch. Biochem. Biophys. 141:155-161. 